\title{
Significance of Parkinsonian Manifestations in Essential Tremor
}

\author{
A.H. Rajput, B. Rozdilsky, L. Ang and Alex Rajput
}

\begin{abstract}
Parkinsonian features, notably resting tremor may be seen in some essential tremor patients but the significance of those is unknown. The reported risk of parkinsonism in essential tremor patients varies from being unchanged to 35 times higher than expected. We studied 9 patients with essential tremor who had autopsies. In 6 of the $9(66 \%)$ resting tremor was noted and in $3(33 \%)$ cases fully developed parkinsonism was noted. The parkinsonism was consequent to neuroleptic usage in 2 and to basal ganglia status lacunaris and cribrosus in one case but no consistent abnormalities were noted in 3 essential tremor only and 3 essential tremor plus resting tremor cases. We conclude that resting tremor is an age-related natural evolution in some essential tremor patients. We recommend that the additional diagnosis of parkinsonism in the essential tremor be made only when resting tremor, bradykinesia and rigidity are all evident. The risk of ideopathic Parkinson's disease in essential tremor cases is similar to the general population.
\end{abstract}

RÉSUMÉ: Signification des manifestations parkinsoniennes dans les cas de tremblement essentiel. Des manifestations parkinsoniennes (PS), particulièrement le tremblement de repos (TR), peuvent être observées chez certains patients souffrant de tremblement essentiel (TE), mais leur signification est inconnue. Selon la littérature, le risque de parkinsonisme (PS) chez les patients souffrant de TE varie de identique à 35 fois celui de la population en général. Nous avons procédé à l'autopsie de 9 patients souffrant de TE. Chez 6 des 9 patients (66\%), un TR avait été noté et chez $3(33 \%)$, un PS évident avait été noté. Le PS était consécutif à l'utilisation de neuroleptiques chez 2 et à l'état lacunaire et criblé des noyaux gris centraux chez un cas. Cependant, aucune anomalie constante n'a été notée chez 3 patients atteints de TE seulement et chez 3 patients avec TE et TR. Nous concluons que le TR est une évolution naturelle, en relation avec l'âge, chez certains patients atteints de TE. Nous recommandons que le diagnostic additionnel de PS chez le patient atteint de TE ne soit posé que lorsque le tremblement de repos, la bradycinésie et la rigidité sont tous évidents. Le risque de maladie de Parkinson idiopathique chez les cas de TE est le même que celui de la population en général.

Can.J. Neurol. Sci. 1993; 20: 114-117

Essential tremor (ET) is the most common pathological tremor in man' and Parkinson syndrome (PS) is a common neurological disorder in the elderly population. ${ }^{2-6}$ Therefore these two conditions may coexist in some individuals. Essential tremor may first manifest in childhood, young adult or old age but PS is concentrated in the later age. When an individual suffers from both ET and PS the usual sequence is an earlier onset of ET and subsequent emergence of PS. Considering that pattern of evolution there is now an active debate on the risk of parkinsonism in the ET patients. ${ }^{7-12}$

The presence of parkinsonian features in the ET cases may indicate: (1) a natural evolution of ET; (2) an incidental coexistence of PS (or IPD); (3) an exaggerated risk of PS (or IPD); or (4) some ET patients may in fact suffer from an unusual tremordominant slowly progressive form of IPD.

The literature dealing with this subject is based exclusively on epidemiological and clinical observations and the conclusions have been contradictory. ${ }^{7.13}$ Parkinson syndrome diagnosis is based on the presence of two of the three - bradykinesia, rigidity and resting tremor. The main reasons for the reported difference for the risk of PS in the ET cases between various studies are: (1) resting tremor (RT) may be seen in some ET cases; ${ }^{14-15}$ (2) cogwheeling phenomena consequent to the coarse tremor in the ET may simulate cogwheel rigidity of PS; :4-15 $^{2}$ and (3) the terms PS and IPD have been used interchangeably.

Parkinson syndrome includes a heterogenous group of disorders, the most common being the idiopathic Parkinson's disease (IPD) which is characterized by marked substantia nigra (SN) neuronal loss and Lewy body (LB) inclusions. ${ }^{16}$ Even if the clinical diagnosis of PS were made correctly in the ET cases, the underlying pathology cannot be predicted accurately in a large proportion of these cases. ${ }^{17-19}$ The pathological findings in the IPD are highly characteristic but there is no known brain pathology in the ET. A carefully conducted clinical study which is followed by pathological verification would therefore help verify the co-existence of IPD in the ET cases.

From the Neurology Division, Department of Medicine (A.H.R.); Department of Pathology (B.R., L.A.); College of Medicine (A.R.), University of Saskatchewan, Saskatoon

Received August 4, 1992. Accepted in final form November 20, 1992

Reprint requests to: Dr. A.H. Rajput, Department of Medicine (Neurology), Royal University Hospital, Saskatoon, Saskatchewan, Canada S7N 0X0 
The objective of this study was to determine: (a) the frequency of parkinsonian features in ET patients, and (b) the significance of those clinical features.

\section{Materials AND MeThOdS}

All patients were seen at the Movement Disorder Clinic (MDC), Royal University Hospital, Saskatoon by one of us (AHR) between 1968 and 1991. The clinical diagnosis of ET was based on a prolonged history of postural or kinetic upper limb or head tremor which could not be attributed to any other neurological or systemic disorder. A positive family history of similar tremor was not essential for the diagnosis.

The additional diagnosis of PS in the ET cases was made only when there was a history of change in the tremor characteristic, and an unequivocal clinical evidence of RT, bradykinesia and rigidity. The tremor amplitude was assessed by visual inspection and was classified as small (fine), medium (moderate), or large (coarse)..$^{20-22}$ All pathological studies were conducted by a qualified neuropathologist (BR or LA) and six of these cases were reported previously. ${ }^{21}$ Several areas of the neocortex, hippocampus, basal ganglia, brainstem, including SN, superior cerebellar peduncles, locus ceruleus, inferior olivary nuclei, cerebellum and the deep cerebellar nuclei were examined routinely in every case. ${ }^{21}$ Special stains, e.g., Bielschowsky and Luxol Fast Blue preparations, were performed when neces- sary for making the proper histological diagnosis. Formal cell count was not conducted at any of the sites.

\section{RESULTS}

Table 1 is a summary of our 9 ET cases. Resting tremor was observed in six (\#1, 2, 3, 7, 8, 9) patients. In three (patients \#1, 2 and 7) all parkinsonian features - RT, bradykinesia and rigidity were noted and therefore an additional diagnosis of PS was made. Of these three, two (patients \#2 and 7) had a history of prolonged neuroleptic usage, and another had brain abnormality which could account for the PS. The final diagnosis in these two cases was drug induced parkinsonism (DIP). The third PS patient (patient \#1) had status lacunaris and cribrosus in the basal ganglia and the striatal dopamine (DA) levels were reduced up to $50 \%$ in some areas. ${ }^{23}$ However, the regional distribution of the DA loss was different from that seen in the IPD. ${ }^{24}$ The PS in this patient was attributed to the basal ganglia pathology. ${ }^{25.26}$ Basal ganglia lacunar state was also noted in patient \#5 who at last clinical evaluation two years before death had no clinical features of PS.

The SN neuronal population was estimated as normal for age in all nine cases and none had LB inclusions at any of the sites examined. There was no consistent gross or histological abnormality in the brain which could be considered as characteristic of ET.

Table 1: Summary of Case Histories

\begin{tabular}{|c|c|c|c|c|c|}
\hline $\begin{array}{l}\text { Case \#, } \\
\text { Sex \& Age } \\
\text { at Death }\end{array}$ & $\begin{array}{l}\text { Age at ET Onset, } \\
\text { Site \& Peak Tremor } \\
\text { Severity Noted }\end{array}$ & $\begin{array}{l}\text { Family } \\
\text { History } \\
\text { of ET }\end{array}$ & $\begin{array}{l}\text { PS - Onset or Age } \\
\text { at Diagnosis and } \\
\text { Manifestations }\end{array}$ & $\begin{array}{l}\text { Other Significant Clinical } \\
\text { Features, Illnesses and } \\
\text { Treatment }\end{array}$ & Pathological Findings \\
\hline $\begin{array}{l}(1) \\
\text { AR-78 yrs. } \\
\text { F }\end{array}$ & $\begin{array}{l}\text { Onset in childhood } \\
\text { UL, coarse post. \& } \\
\text { kine. vert. head } \\
\text { tremor - medium } \\
\text { amplitude }\end{array}$ & $\begin{array}{l}\text { +ve-son, } \\
\text { daughter, } \\
\text { granddaughter } \\
\text { (all examined) }\end{array}$ & $\begin{array}{l}\text { Onset at } 60 \text { yrs. }(R) \\
\text { metacarpophalangeal } \\
\text { joints, }(R) \text { ankles, } \\
\text { reduced facial } \\
\text { expression. Rig. } \\
\text { more }(R) \text { than }(L) \text {, } \\
\text { post. instab.; Brady. } \\
\text { more }(R) \text { than }(L)\end{array}$ & $\begin{array}{l}\text { ET improved with alcohol } \\
\& \text { propanolol each. No PS } \\
\text { improvement on levodopa or } \\
\text { anticholinergics. Had MI at } 60 \\
\& \text { (L) cerebral stroke at age } \\
77 \text { yrs. }\end{array}$ & $\begin{array}{l}\text { Died of acute MI. Grossly } \\
\text { moderate cerebral } \\
\text { atherosclerosis, (L) insular old } \\
\text { infarct. Micro: infarct (L) } \\
\text { cerebral insular cort. adjacent } \\
\text { white matter. Status lacunaris in } \\
\text { (L) GP \& Put. Normal SN for } \\
\text { age. No LB. }\end{array}$ \\
\hline
\end{tabular}

\begin{tabular}{|c|c|c|c|}
\hline $\begin{array}{l}(2) \\
\text { DR-58 yrs. } \\
\text { F }\end{array}$ & $\begin{array}{l}\text { Onset in childhood } \\
\text { UL - medium } \\
\text { amplitude; Head - } \\
\text { small amplitude }\end{array}$ & -ve & $\begin{array}{l}\text { Diagnosed at age } 54 \\
\text { yrs. Bil. UL resting } \\
\text { tremor rig. \& brady. } \\
\text { and post. instab. }\end{array}$ \\
\hline
\end{tabular}
small amplitude
Had severe depression \& anxiety, needed ECT \& longterm neuroleptics. Attempted suicide $x 3$. Could not hold job due to tremor and anxiety. Did not tolerate levodopa. Had MI at $55 \mathrm{yrs}$.

\begin{tabular}{|c|c|c|c|}
\hline $\begin{array}{l}(3) \\
\text { ET-69 yrs. } \\
\text { F }\end{array}$ & $\begin{array}{l}\text { Onset at age } 51 \text { yrs. } \\
\text { UL post. \& kinet. } \\
\text { tremor. Vertical head } \\
\text { tremor. Intermittent } \\
\text { resting tremor }(\mathbf{R}) \\
\text { finger of small } \\
\text { amplitude }\end{array}$ & +ve mother & No PS diagnosis \\
\hline $\begin{array}{l}\text { (4) } \\
\text { GB-SI yrs. } \\
M\end{array}$ & $\begin{array}{l}\text { Onset in childhood } \\
\text { UL, post. \& kine. - } \\
\text { small amplitude }\end{array}$ & $\begin{array}{l}\text { +ve father, } \\
\text { brother \& } \\
\text { cousin }\end{array}$ & No PS diagnosis \\
\hline $\begin{array}{l}\text { (5) } \\
\text { MW-83 yrs. } \\
\text { F }\end{array}$ & $\begin{array}{l}\text { Onset at } 25 \text { yrs. } \\
\text { Head tremor - coarse } \\
\text { UL post. \& kine. } \\
\text { tremor - fine }\end{array}$ & $-v e$ & No PS diagnosis \\
\hline
\end{tabular}

\section{Leukemia}

Hypertension, alcohol excess drank to relieve tremor

Abdominal aortic aneurysm. Was well adjusted \& lived in her home independently until death. Last evaluation 2 years prior to death
Died following coronary artery bypass surgery. Brain - normal gross \& histological. Normal SN cells. No LB.

Died of complication of leukemia. Normal gross \& histological exam of brain. No LB.

Died of presumed cardiac dysrhythmia. Normal gross \& histological exam of brain. No LB.

Died of ruptured abdominal aortic aneurysm. Brain - grossly normal. Bilateral basal ganglia status lacunaris. No LB.

(Continued) 
Table 1: Summary of Case Histories (Continued)

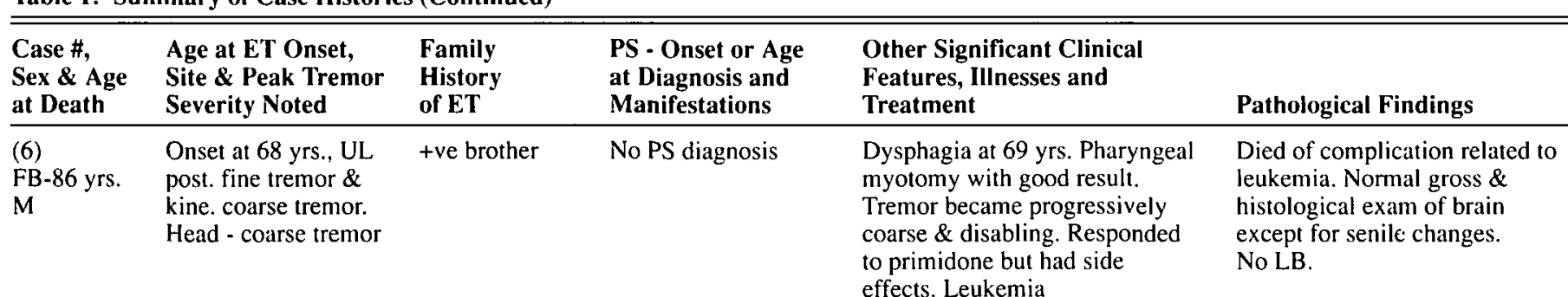

$\begin{array}{ll}(7) & \text { Onset at } 61 \text { yrs. UL +ve father } \\ \text { LH-67 yrs. } & \begin{array}{l}\text { post. \& kine. - } \\ \text { moderate amplitude }\end{array}\end{array}$

$\begin{array}{ll}(8) & \text { Onset a age } 30 \text { yrs. } \\ \text { KS-81 yrs. } & \text { UL post. \& kine. - } \\ \text { M } & \text { medium amplitude } \\ & \text { (R) finger resting } \\ & \text { tremor - small } \\ & \text { amplitude }\end{array}$
$\begin{array}{ll}\text { (9) } & \text { Onset at age } 36 \text { yrs } \\ \text { KM-62 yrs. UL post. \& kine. - }\end{array}$ F coarse tremor. (L) \& (R) thumb resting tremor - small amplitude sister

-ve
Diagnosed at age 65 yrs - resting tremor, (R) UL more than (L). Bil. rigidity \& brady.

+ve father, $\quad$ No PS diagnosis
sister
effects. Leukemia

Propanolol $20 \times 2$ helped tremor. nitroglycerine. Long history of affective disorder, paranoia was on neuroleptics \& received ECT anxiety. (L) frozen shoulder. No improvement on amantadine

No persistent PS manifestations Angina pectoris treated with

Tendency to depression \&

Died of M.I. Grossly \& microscopically normal brain. No LB.

\author{
Died of cardio-respiratory \\ arrest. Grossly \& \\ microscopically normal brain \\ for age. No LB.
}

Depression towards the end. MRI - Brain normal
Died of neuroleptic malignant syndrome. Hemorrhagic lesions consistent with neuroleptic malignant syndrome. Foci of perivascular calcification in basal ganglia. Normal SN. No LB.

$$
\begin{aligned}
& \text { LL }=\text { Lower Limb } \\
& \text { UL }=\text { Upper Limb } \\
& \text { Bil }=\text { Bilateral } \\
& \text {-ve }=\text { Negative } \\
& \text { +ve }=\text { Positive } \\
& \text { Kine = Kinetic Tremor } \\
& \text { Post }=\text { Postural Tremor } \\
& \text { Rig = Rigidity } \\
& \text { Brady = Bradykinesia } \\
& \text { PS = Parkinson Syndrome }
\end{aligned}
$$

$$
\begin{aligned}
& \text { LB }=\text { Lewy Body Inclusions } \\
& \text { ET = Essential Tremor } \\
& \text { SN }=\text { Substantia Nigra } \\
& \text { GB }=\text { Globus Pallidus } \\
& \text { Put }=\text { Putamen } \\
& \text { MI = Myocardial Infarct } \\
& \text { (L) = Left } \\
& \text { (R) = Right } \\
& \text { Cort = Cortex } \\
& \text { Vert = Vertical }
\end{aligned}
$$

\author{
ECT $=$ Electroconvulsive Therapy \\ $\mathrm{MRI}=$ Magnetic Resonance Imaging \\ Post. Instab. = Postural Instability
}

\section{Discussion}

Resting tremor which is one of three major clinical manifestations in PS was noted in $66 \%$ of our ET patients. In three of those (\#1, \#2 and \#7) there was an additional clinical evidence of PS - bradykinesia and rigidity. In the other three cases (\#3, \#8 and \#9) RT was the only manifestation suggestive of PS diagnosis.

The subgroup with RT without bradykinesia and rigidity, we believe represents a natural late stage evolution in some ET patients. ${ }^{14.15}$ The reasons for the emergence of RT in the ET cases are unknown. Our patients had no pathology in the nigrostriatal system or at any other site which may produce RT. All three ET plus RT cases who had no other PS features, had history of ET of more than 10 years duration and each was older than 60 years when the RT emerged. It is possible that some age related changes resulted in this clinical evolution. Striatal DA loss, a characteristic finding in the IPD (which often manifests as $\mathrm{RT}^{20}$ ) is also seen in normal aging, ${ }^{27}$ and may have contributed to the development of RT. Age-related striatal DA loss alone however does not produce RT in the normal elderly. It is conceivable that the ET diathesis primes these individuals to developing RT when the age-related striatal DA decline reaches a critical level.
In three $(33 \%)$ of our patients, there was an unequivocal evidence of PS, though none had pathological features typical of IPD. ${ }^{16}$ Two cases (\#2 and \#7) had DIP and no pathological findings in the brain. In the third patient (\#1) with the diagnoses of ET and PS, basal ganglia status lacunaris and cribrosus were detected. Such abnormalities have been reported to produce PS in some individuals. ${ }^{25.26}$ One additional patient (\#5) had similar pathology, but there was no clinically documented PS. The last assessment in this patient was done two years prior to death. It is possible that the basal ganglia pathology in this patient evolved subsequent to the last neurological assessment. We do not believe that the ET predisposed to DIP in our two (\#2 and \#7) patients. Because of the age-related striatal DA decline the elderly are more susceptible to neuroleptic stress and consequently the DIP. The pathological findings of basal ganglia status cribrosus and lacunaris which we believe was the basis of PS in patient \#1 was unrelated to ET. Thus in none of the three ET patients who had PS did the pre-existing ET enhance the susceptibility to PS and none had IPD pathology. ${ }^{16}$ We conclude that the PS in these ET cases was incidental.

Our report of 9 ET cases by most standards of clinico-pathological studies in common neurological disorders is small. However it is the largest of its kind in the ET patients in the 
literature so far. These patients were studied for a long time seven of the nine cases were followed for more than 10 years before coming to autopsy and 5 had suffered from ET for more than 30 years at the time of death. Thus, in spite of the limitations consequent to the size of the study, because of the careful clinical and pathological observations, questions pertaining to the risk of IPD can be addressed satisfactorily.

Definite clinico-pathological correlation between SN neuronal loss and LB inclusions in the IPD was first made in 1919. ${ }^{28.29}$ Incidental LB inclusions are reported in non-parkinsonian general population between 6 th and 9 th decade in $3.8 \%$ to $12.8 \%$ of the autopsied subjects. ${ }^{30.31}$ Individuals with incidental LB findings are regarded by some observers as suffering from pre-clinical IPD. ${ }^{30}$ Pathological evidence of definite ${ }^{16}$ and preclinical IPD ${ }^{30}$ may therefore be used to assess the risk of IPD in the autopsied ET patients. None of our nine patients or the six ET autopsies reported by others ${ }^{1.32-36}$ since 1919 had pathological findings indicative of definite or preclinical IPD.

If the risk of IPD in the ET patients were merely twice that in the general population, rather than the 24 to 35 fold increase suggested in some studies, ${ }^{8.9}$ we would expect to find LB inclusions in $7 \%(3.8 \% \times 2)$ to $25 \%(12.8 \% \times 2)$ of the autopsied ET patients. However none of the 15 patients reported so far had LB inclusions. Thus the autopsy literature on ET indicates that ET does not increase the risk of IPD. ${ }^{7} 10,11$ Our observations also mitigate against the possibility that some ET patients may suffer from an unusual form of IPD. Considering that RT may represent a natural evolution in some cases we propose that the additional diagnosis of PS be made only when all three cardinal features - RT, rigidity and bradykinesia are identifiable in an ET patient.

\section{ACKNOWLEDGEMENTS}

Funding for this study was supported by a grant from the Saskatchewan Parkinson's Disease Foundation.

\section{REFERENCES}

1. Larsen TA, Calne DB. Essential tremor. Clin Neuropharmacol 1983; 6 (3): 185-206.

2. Kurland LT. Epidemiology: incidence, geographic distribution and genetic considerations. In: Fields WS, ed. Pathogenesis and Treatment of Parkinsonism. Springfield, Illinois: Thomas 1958: $5-43$.

3. Martila RJ. Epidemiology. In: Koller WC, ed. Handbook of Parkinson's Disease. New York: Marcel Dekker Inc. 1987: 35-50.

4. Bharucha NE, Bharucha EP, Bharucha AE, et al. Prevalence of Parkinson's disease in the Parsi Community of Bombay, India. Arch Neurol 1988; 45: 1321-1323.

5. Schoenberg BS, Anderson DW, Haerer AF. Prevalence of Parkinson's Disease in the Biracial Population of Copiah County, Mississippi. Neurology 1985; 35(6): 841-845.

6. Rajput AH, Offord KP, Beard CM, Kurland LT. Epidemiology of Parkinsonism: incidence, classification, and mortality. Ann Neurol 1984; 16: 278-282.

7. Rajput AH, Offord KP, Beard CM, Kurland LT. Essential tremor in Rochester, Minnesota: a 45-year study. J Neurol Neurosurg Psychiatry 1984; 47: 466-470.

8. Geraghty JJ, Jankovic J, Zetusky WJ. Association between essential tremor and Parkinson's disease. Ann Neurol 1985; 17: 329-333.

9. Hornabrook RW, Nagurney JT. Essential tremor in Papua, New Guinea. Brain 1976; 99: 659-672.

10. Cleeves L, Findley LJ, Koller W. Lack of association between essential tremor and Parkinson's disease. Ann Neurol 1988; 24: $23-26$
11. Lang AE, Kierans C, Blair RDG. Association between familial tremor and Parkinson's disease. Ann Neurol 1986; 19: 306-307.

12. Marttila RJ, Rautakorpi I, Rinne UK. The relation of essential tremor to Parkinson's disease. J Neurol Neurosurg Psychiatry 1984; 47: 734-735.

13. Roy M, Boyer L, Barbeau A. A prospective study of 50 cases of familial Parkinson's disease. Can J Neurol Sci 1983; 10: 37-42.

14. Findley LJ, Gresty MA, Halmagyi GM. Tremor and cogwheel phenomena and clonus in Parkinson's disease. J Neurol Neurosurg Psychiatry $1981 ; 44:$ 534-546.

15. Salisachs P, Findley LJ. Problems in the differential diagnosis of essential tremor. In: Finley LJ, Capildeo R, eds. Movement Disorders: Tremor. London \& Basingstoke: MacMillan Press Ltd. 1984: 219-224.

16. Duvoisin R, Golbe LI. Toward a definition of Parkinson's disease. Neurology 1989; 39: 746.

17. Rajput AH. Rozdilsky B, Rajput Alex H. Accuracy of clinical diagnosis in parkinsonism - a prospective study. Can J Neurol Sci 1991: 18: 275-278.

18. Hughes AJ, Daniel SE, Kilford L, Lees AJ. Accuracy of clinical diagnosis of idiopathic Parkinson's disease: a clinico-pathological study of 100 cases. J Neurol Neurosurg Psychiatry 1992; 55: $181-184$.

19. Forno LS. Pathology of parkinsonism: a preliminary report of 24 cases. J Neurosurg 1966; 24: 266-271.

20. Rajput AH. Rozdilsky B, Ang L. Occurrence of resting tremor in Parkinson's disease. Neurology 1991; 41: 1298-1299.

21. Rajput AH, Rozdilsky B, Ang L, Rajput Alex. Clinicopathological observations in essential tremor. Report of 6 cases. Neurology 1991; 41: 1422-1424.

22. Rajput $\mathrm{AH}$, Stern W, Laverty WH. Chronic low dose therapy in Parkinson's disease: an argument for delaying levodopa therapy. Neurology 1984; 34(8): 991-996.

23. Rajput AH, Rozdilsky B, Kish S, Hornykiewicz O. Parkinson's disease association with essential tremor. Mov Disord 1990; 5 (Suppl 1): 1414 (Abstract).

24. Kish SJ, Shannak K, Hornykiewicz O. Uneven pattern of dopamine loss in the striatum of patients with idiopathic Parkinson's disease. N Engl J Med 1988; 318: 876-880.

25. Murrow RW, Schwieger GD, Kepes JJ, Koller WC. Parkinsonism due to a basal ganglia lacunar state: clinicopathologic correlation. Neurology 1990; 40: 897-900.

26. Tolosa ES, Santamaria JH. Parkinsonism and basal ganglia infarcts. Neurology 1984; 34: 1516-1518.

27. Kish SJ, Shannak K, Rajput A, Deck JHN, Hornykiewicz O. Aging produces a specific pattern of striatal dopamine loss: implications for the etiology of idiopathic Parkinson's disease. J Neurochem 1992; 58: 642-648.

28. Jellinger $\mathrm{K}$. The pathology of parkinsonism. In: Marsden CD, Fahn S, eds. Movement Disorders 2. London: Butterworths and Co. 1987; 124-165.

29. Parkinson J. A bicentenary volume of papers dealing with Parkinson's disease. In: Critchley M, McMenemey WH, Walshe FMR, Greenfield JG, eds. London: MacMillan 1955.

30. Gibbs WRG, Lees AJ. The relevance of the lewy body to the pathogenesis of idiopathic Parkinson's disease. J Neurol Neurosurg Psychiatry 1988; 51: 745-752.

31. Gibb WR. Idiopathic Parkinson's disease and the lewy body disorders. Neuropathol Appl Neurobiol 1986; 12: 223-234.

32. Hassler R. Zur pathologischen Anatomie des senilen und des parkinsonistischen tremor. J Psychol Neurol (Lpz) 1939; 49: 193-230.

33. Herskovits E, Blackwood W. Essential (familial, hereditary) tremor: a case report. J Neurol Neurosurg Psychiatry 1969; 32: 509-511.

34. Mylle G. van Bogaert L. Etudes anatomo-cliniques de syndromes hypercinetiques complexes. Mschr Psychiat Neurol 1940; 103: $28-43$.

35. Mylle G, van Bogaert L. Du tremblement essential non familial. Mschr Psychiat Neurol 1948; 115: 80-90.

36. Lapresle J, Rondot R, Said G. Tremblement idiopathique de repos, d'attitude et d'action: Etude anatomo-clinique d'une observation. Revue Neurologique, Paris 1974; 130: 343-348. 